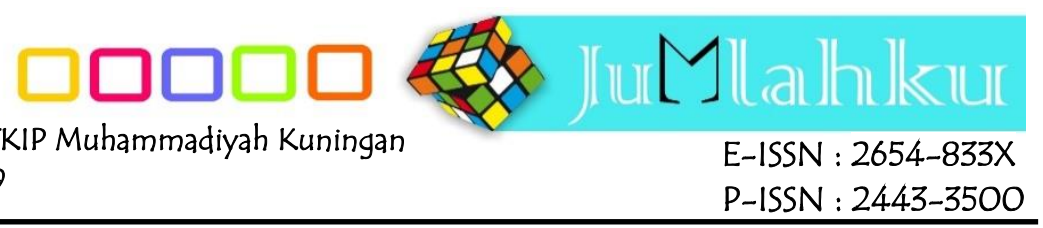

Jurnal Matematika Ilmiah STKIP Muhammadiyah Kuningan Vol. 5 No.2 November 2019

P-ISSN : 2443-3500

\title{
Penerapan Strategi Pembelajaran Active Knowledge Sharing Terhadap Kemampuan Pemahaman Matematika
}

\author{
Firda Halawatia)
}

a) Universitas Islam Al-Ihya Kuningan

fbayasut90@yahoo.com

\begin{tabular}{l}
\hline \multicolumn{1}{c}{ Article Info } \\
\hline Keywords : active \\
knowledge sharing strategy, \\
mathematical understanding \\
ability
\end{tabular}

Submited: $10 / 31 / 2019$

Published: $12 / 4 / 2019$
This study uses a Pre-experimental research method with one group pretest posttest design. The population in this study were all students of MTSN 4 Kuningan, amounting to 748 students. The sampling technique uses purposive sampling technique. The sample in this study was taken from two classes, namely class VII $E$ as an experimental class totaling 31 students and class VII $F$ as a control class of 31 students. Then all samples used were 62 students. The test is given in the initial test (pretest) and final test (posttest). Before the test is given, it is tested first in the form of test instruments, validity, reliability, the level of difficulty of the questions, the distinguishing power of the questions is analyzed first. The analysis of hypothesis testing data in this study uses the Independent Samples T-Test which was previously tested for normality and homogeneity. The results of this study indicate (1) the use of the MTSN 4 Kuningan active knowledge sharing strategy runs well and effectively. (2) After the initial and final test results of the two classes were analyzed, finally the average results of the initial test of the experimental class was 52.10 and the final test was 73.06 so that from the average of the initial and final tests there was an increase of $40.23 \%$. And the control class got an average of initial tests of 51.77 and final tests of 67.56 there was an increase of $30.50 \%$. This is confirmed by the average difference test (t-test) obtained by tcounts $t$ table, which is 2.163> 1.670 and the significance value is below 0.05 , which is $0.03<0.05$. Based on the $\mathrm{N}$-Gain test, the $\mathrm{N}$-Gain value obtained from the experimental class 0.55 was a moderate criterion and for the control class 0.41 that had a moderate criterion. (3) Based on these results it shows that Ha was accepted and Ho was rejected. So it can be concluded that there is an influence on the implementation of active knowledge sharing strategies on the ability to understand mathematics.

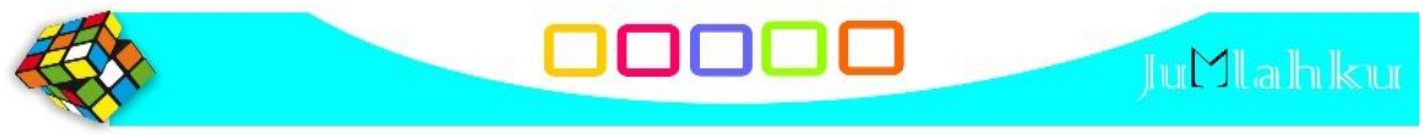


Kata Kunci: strategi active knowledge sharing, kemampuan pemahaman

\section{Abstrak}

Tujuan penelitian ini adalah (1) untuk mengetahui penerapan strategi pembelajaran active konwledge sharing; (2) untuk mengetahui tingkat kemampuan pemahaman matematika (3) untuk mengetahui penerapan strategi pembelajaran active knowledge sharing terhadap kemampuan pemahaman matematika. Penelitian ini menggunakan metode penelitian Preeksperimental dengan desain one group pretest posttest. Populasi dalam penelitian ini adalah seluruh siswa MTSN 4 Kuningan yang berjumlah 748 siswa. Teknik pengambilan sampel menggunakan teknik purposive sampling. Sampel dalam penelitian ini diambil dari dua kelas yaitu kelas VII E sebagai kelas eksperimen yang berjumlah 31 siswa dan kelas VII F sebagai kelas kontrol yang berjumlah 31 siswa. Kemudian semua sampel yang digunakan adalah 62 siswa. Tes diberikan dalam tes awal (pretest) dan tes akhir (posttest). Sebelum tes diberikan diuji terlebih dahulu instrumen tes berupa, validitas, reliabilitas, tingkat kesulitan soal, daya pembeda soal dianalisis terlebih dahulu. Analisis data pengujian hipotesis dalam penelitian ini menggunakan Independent Samples T-Test yang sebelumnya telah diuji untuk normalitas dan homogenitas. Hasil penelitian ini menunjukkan (1) penggunaan strategi active knowledge sharing MTSN 4 Kuningan berjalan dengan baik dan efektif. (2) Setelah data hasil tes awal dan akhir dari dua kelas dianalisis, akhirnya hasil rata-rata tes awal kelas eksperimen adalah 52,10 dan tes akhir adalah 73,06 sehingga dari rata-rata tes awal dan akhir ada meningkat 40,23\%. Serta kelas kontrol memperoleh rata-rata rata-rata tes awal 51,77 dan tes akhir 67,56 ada peningkatan $30,50 \%$. Hal ini diperkuat oleh uji perbedaan rata-rata (t-test) yang diperoleh dengan thitung $>$ ttabel, yaitu 2,163> 1,670 dan nilai signifikansi di bawah 0,05, yaitu $0,03<0,05$. Berdasarkan uji N-Gain, nilai N-Gain yang diperoleh dari kelas eksperimen 0,55 adalah kriteria sedang dan untuk kelas kontrol 0,41 yang memiliki kriteria sedang. (3) Berdasarkan hasil ini menunjukkan bahwa Ha diterima dan Ho ditolak. Jadi dapat disimpulkan bahwa terdapat pengaruh penerapan strategi active knowledge sharing terhadap kemampuan pemahaman matematika.

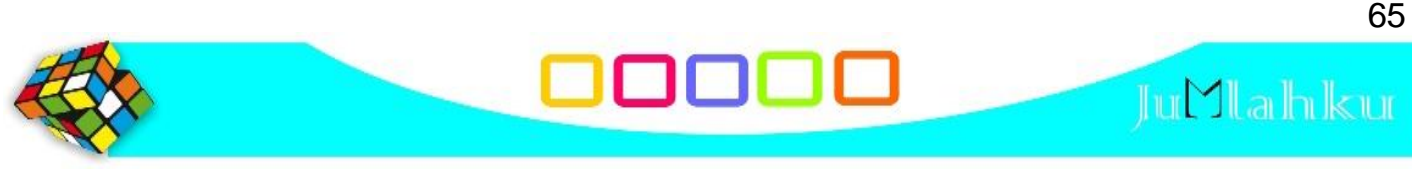




\section{PENDAHULUAN}

Masalah Pendidikan merupakan sebuah proses panjang yang dialami oleh manusia sebagai makhluk pembelajar. Pendidikan berlangsung sejak lahir hingga akhirhayat. Pada dasarnya, semua manusia membutuhkan pendidikan karena tanpa pendidikan, manusia akan kesulitan saat menghadapi suatu masalah. Manusia akan kesulitan bahkan kebingungan dalam menemukan solusi atas segala permasalahan yang dihadapinya. Mengenai pendidikan di Indonesia telah di jelaskan dalam Undang Undang Sistem Pendidikan Nasional no. 20 Tahun 2003, fungsi pendidikan nasional adalah mengembangkan kemampuan, membentuk watak dan peradaban bangsa agar menjadi manusia yang beriman dan bertakwa kepada Allah, berakhlak mulia, sehat, berilmu, cakap, kreatif, mandiri, dan menjadi warga negara yang demokratis serta bertanggung jawab. Mewujudkan fungsi Pendidikan Nasional tersebut tidaklah mudah, sekolah harus memperhatikan instrumen yang ada di sekolah, seperti kualitas para pendidik, media pembelajaran yang mencukupi, strategi pembelajaran, motivasi belajar, fasilitas pembelajran dan lainlain. Hal ini yang dapat menunjang tercapainya fungsi Pendidikan Nasional dengan baik, akan tetapi pada kenyataannya kualitas pendidikan di Indonesia masih kurang memuaskan.

Rendahnya kualitas pendidikan di Indonesia dapat dilihat dalam Perkembangan dan Kondisi Terkini Pendidikan Indonesia, dilihat dari data pemetaan Learing Curve, Indonesia berada pada peringkat 40 .

Tabel 1 Pemetaan The Learning Curve 2013

\begin{tabular}{|l|l|c|c|c|c|c|c|}
\hline \multirow{2}{*}{ Number } & \multirow{2}{*}{ Country } & \multicolumn{2}{|l|}{ Overall Index } & \multicolumn{2}{l|}{$\begin{array}{l}\text { Cognitive } \\
\text { Skills }\end{array}$} & \multicolumn{2}{l|}{$\begin{array}{l}\text { Educational } \\
\text { Attainment }\end{array}$} \\
\cline { 3 - 9 } & & Rank & Score & Rank & Score & Rank & Score \\
\hline & Romania & 31 & $-0,44$ & 31 & $-0,62$ & 28 & $-0,08$ \\
\hline & Chile & 32 & $-0,79$ & 34 & $-1,06$ & 32 & $-0,26$ \\
\hline & Greece & 33 & $-0,86$ & 33 & $-0,83$ & 35 & $-0,93$ \\
\hline & Turkey & 34 & $-0,94$ & 32 & $-0,68$ & 38 & $-1,46$ \\
\hline & Thailand & 35 & $-1,16$ & 35 & $-1,09$ & 37 & $-1,30$ \\
\hline & Colombia & 36 & $-1,25$ & 35 & $-1,56$ & 34 & $-0,64$ \\
\hline
\end{tabular}




\begin{tabular}{|c|c|c|c|c|c|c|c|}
\hline \multirow[t]{2}{*}{ Number } & \multirow[t]{2}{*}{ Country } & \multicolumn{2}{|c|}{ Overall Index } & \multicolumn{2}{|c|}{$\begin{array}{l}\text { Cognitive } \\
\text { Skills }\end{array}$} & \multicolumn{2}{|c|}{$\begin{array}{l}\text { Educational } \\
\text { Attainment }\end{array}$} \\
\hline & & Rank & Score & Rank & Score & Rank & Score \\
\hline & Argentina & 37 & $-1,49$ & 40 & $-2,14$ & 31 & $-0,20$ \\
\hline & Brazil & 38 & $-1,73$ & 39 & $-2,06$ & 36 & $-1,08$ \\
\hline & Mexico & 39 & $-1,76$ & 38 & $-1,78$ & 39 & $-1,73$ \\
\hline & Indonesia & 40 & $-1,84$ & 37 & -1.71 & 40 & $-2,11$ \\
\hline
\end{tabular}

Sumber : Pemetaan, The Learning Curve 2013

Tabel di atas menunjukan bahwa jelas ada masalah dalam Sistem Pendidikan di Indonesia diantaranya adalah seperti kekeliruan paradigma pendidikan yang melandasi keseluruhan sistem pendidikan, mahalnya pembiayaan pendidikan, rendahnya prestasi siswa, rendahnya sarana fisik, rendahnya kualitas guru, rendahnya kesejahteraan guru, termasuk rendahnya pemahaman siswa dan sebagainya. Hal tersebut mengidentifikasikan bahwa sistem pendidikan di Indonesia belum begitu berhasil dalam mewujudkan tujuan pendidikan.

Seperti pada kenyataanya dalam proses belajar mengajar di kelas, peserta didik sudah dibiasakan hanya menjadi pendengar yang setia. Pembelajaran di sekolah-sekolah kita cenderung hanya mendorong siswa "belajar untuk tahu" atau sering disebut dengan "learning to know".
Disini peserta didik hanya belajar untuk tau, sehingga setelah siswa mengetahui pembelajaran tersebut mereka enggan untuk memahami lebih mendalam,kebanyakan dari mereka menganggap tugas belajar mereka telah selesai jika telah menempuh ujian dan dinyatakan lulus dalam ujian tersebut. Mereka tidak mempunyai kemauan untuk mengembangkan diri lebih baik dalam pengetahuan ataupun pendidikannya, baik dilingkungan masyarakat maupun lingkungan kerja, inilah yang menjadi salah satu kekeliruan paradigma pendidikan di Indosenia.

Menurut Daud Perkins (Uno, 2009:172), pemahaman merujuk pada apa yang dapat seseorang lakukan dengan informasi itu, dari pada apa yang mereka ingat. Pengetahuan melibatkan tindakan dari pada penguasaan. Ketika para siswa mengerti sesuatu, mereka dapat menjelaskan konsep-konsep dalam kalimat mereka sendiri, 
menggunakan informasi dengan tepat dalam konteks baru, membuat analogi baru, dan generalisasi. Untuk memberikan pemahaman terhadap siswa harus adanya strategi khusus yang di. Maka dari itu dalam kegiatan pembelajaran penting adanya strategi agar menarik hasil siswa dan juga memotivasi siswa agar mudah untuk memahami dan juga mengerti dengan materi yang akan disampaikan. Namun pada kenyataannya dari dulu hingga sekarang ini kegiatan pembelajaran hanya berpusat kepada guru (teacher centre), sehingga siswa terkesan tidak aktif dan membuat siswa jenuh akan pelajaran yang disampaikan oleh guru, yang pada akhirnya membuat hasil belajar siswa menurun dalam pembelajaran tersebut. Sudah barang tentu setiap guru menginginkan siswanya mendapatkan hasil yang baik dan juga menginginkan suasana kelas yang kondusif dan juga siswa yang aktif dan ikut serta dalam pembelajaran.

Salah satu strategi belajar yang dapat meningkatkan hasil belajar siswa dan dapat pula meningkatkan keaktifan siswa dalam proses pembelajaran serta diharapkan dapat meningkatkan pemahaman siswa pada mata pelajaran tertentu yaitu strategi pembelajaran aktif dengan active knowledge sharing. Dengan menggunakan strategi active knowledge sharing ini diharapkan dapat membuat siswa lebih aktif dalam proses belajar dan juga akan lebih cepat dalam memahami pelajaran tersebut.

Menurut (Nafia 2012:29) Strategi pembelajaran active knowledge sharing (saling tukar pengetahuan) adalah salah satu strategi yang dapat membuat siswa lebih siap dan cepat dalam memahami pelajaran, karna dalam strategi ini di tuntut untuk aktif dalam bertanya ataupun menjawab pertanyaanpertanyaan dan siswa saling bertukar pengetahuan yang ia ketahui, dengan bertukar fikiran dipercaya akan membuat siswa lebih cepat dalam memahami materi pembelajaran.

Pendapat lain tentang pengertian active knowledge sharing dikemukakan oleh (Zaini, 2007:22), Strategi active knowledge sharing ini adalah strategi yang mendukung kerja sama tim, dan dalam tim tersebut harus saling bekeja sama satu sama lain dalam menjawab pertanyaan. Biasanya siswa akan lebih mudah mengungkapkan pendapatnya ataupun pengetahuannya kepada teman dibanding kepada guru, dari sinilah guru dapat menilai keaktifan

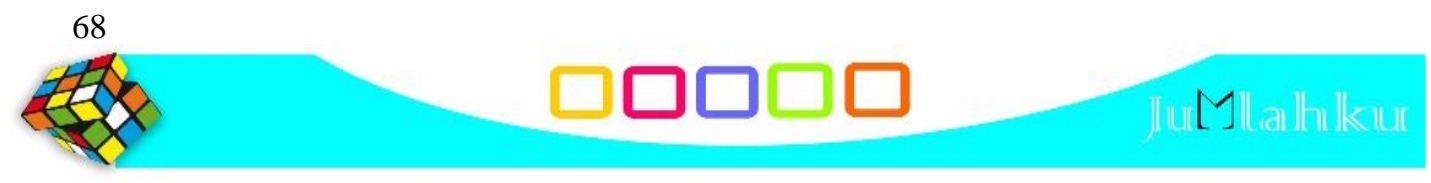


siswa dan juga pemahaman siswa, strategi ini juga sangat cocok digunakan untuk siswa yang malu untuk bertanya atupun memberikan pendapat, karna dalam strategi ini siswa yang tidak dapat menjawab pertanyaan yang diajukan harus berkeliling kepada temannya untuk mendapatkan jawaban.

Berdasarkan uraian di atas penelitian ini bertujuan untuk mengetahui penerapan strategi pembelajaran active konwledge sharing; untuk mengetahui kemampuan pemahaman matematika dan untuk mengetahui penerapan strategi pembelajaran active knowledge sharing terhadap kemampuan pemahaman

\section{METODE}

Metode penelitian yang di gunakan dalam penelitian ini adalah metode penelitian Pre-experimental dengan one group pretest posttest design. Dalam penelitian ini, subyek penelitian terlebih dahulu diberikan tes awal (pretest). Setelah diberikan tes awal, selanjutnya kepada siswa tersebut diberikan perlakuan, yaitu pembelajaran matematika dengan penerapan strategi pembelajaran active knowledge sharing. Setelah selesai pembelajaran selanjutnya seluruh siswa diberikan tes akhir (posttest).

Desain penelitian

Desain penelitian ini dilakukan dalam penelitian ini yakni sebagai berikut : matematika.

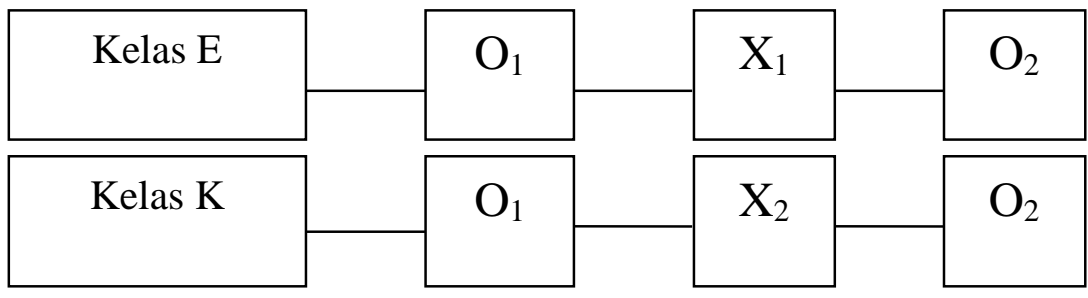

Gambar 1. Desain Penelitian

Populasi dan sampel

Populasi dalam penelitian ini adalah seluruh siswa di MTSn 4 Kuningan yang berjumlah 748 siswa. Teknik

sampel

menggunakan teknik purposive sampling, artinya pengambilan subyek didasarkan atas adanya tujuan tertentu. Tujuan tertentu tersebut yaitu karena materi bilangan bulat hanya 
ada di kelas VII. Sampel dalam penelitian ini diambil dari dua kelas yaitu kelas VII E sebagai kelas eksperimen yang berjumlah 31 siswa dan kelas VII F sebagai kelas kontrol yang berjumlah 31 siswa. Kemudian semua sampel yang digunakan adalah 62 siswa.

Instrument Pengumpulan Data Instrumen yang digunakan dalam penelitian ini adalah berupa tes. Test adalah alat untuk mengukur hasil belajar siswa. Jenis tes yang digunakan adalah tes penguasaan yakni tes awal (pretest) dan tes akhir (posttest), adapun pengertian dari tes awal adalah tes yang diberikan sebelum siswa diberikan perlakuan untuk mengetahui sejauh mana pemahaman siswa terhadap materi yang akan disampaikan, sedangkan tes akhir adalah tes yang diberikan sesudah proses pembelajaran berlangsung, untuk mengetahui sejauh mana daya serap siswa terhadap materi yang sudah diajarkan. Instrumen penelitian harus memenuhi kriteria validitas, reliabilitas, tingkat kesukaran dan daya pembeda soal agar penggunaanya dalam suatu penelitian dapat menghasilkan data yang akurat dan objektif.

Teknik Analisis Data
Teknis analisis data pada penelitian ini adalah menggunakan uji independent sample t-test. Alat pengumpul data pada penelitian ini adalah tes, yang selanjutnya akan dianalisis dengan uji prasyarat yang meliputi uji normalitas dan uji homogenitas dilanjutkan dengan uji independent sample t-test.

\section{HASIL DAN PEMBAHASAN}

Penelitian ini dilakukan terhadap siswa MTSN 4 Kuningan yang berjumlah 748 siswa. Teknik pengambilan sampel menggunakan teknik purposive sampling. Sampel dalam penelitian ini diambil dari dua kelas yaitu kelas VII E sebagai kelas eksperimen yang berjumlah 31 siswa dan kelas VII F sebagai kelas kontrol yang berjumlah 31 siswa.. Setelah instrumen soal dibuat dilakukan terlebih dahulu analisis uji coba instrumen penelitian berupa uji validitas, reliabilitas, uji tingkat kesukaran soal dan uji daya pembeda soal. Adapun langkah selanjutnya peneliti mengadakan proses pembelajaran dikelas yang dijadikan sebagai sampel penelitian yaitu kelas kontrol dikelas VII $F$ dengan menggunakan strategi pembelajaran problem based learning dan kelas eksperimen yaitu kelas VII E dengan 
menggunakan strategi pembelajaran active knowledge sharing. Sebelum menyampaikan materi pembelajaran peneliti terlebih dahulu memberikan tes awal (pretest) kepada dua kelas tersebut dengan tujuan mengetahui kemampuan pemahaman siswa. Adapun proses pembelajaran dikelas eksperimen dengan menggunakan strategi pembelajaran active knowledge sharing dan kelas kontrol dengan menggunakan strategi pembelajaran problem based learning secara umum dapat diterima dan diikuti dengan baik oleh siswa.
Setelah akhir pertemuan materi diberikan tes akhir (posttest) yang bertujuan untuk mengetahui penguasaan terhadap materi yang telah disampaikan dikelas eksperimen dan kelas kontrol. Setelah diperoleh nilai prestest dan postest untuk kelas eksperimen dan kelas kontrol dilanjutkan dengan uji normalitas dan uji homogenitas dan uji independent sample t-test. Deskripsi data hasil penelitian nilai pretest kelas kontrol dan kelas eksperimen siswa disajikan pada tabel berikut :

Tabel 2. Nilai Pretest Kelas Kontrol dan Kelas Eksperimen

\begin{tabular}{|c|r|r|}
\hline & Pretest_Kelas_Kontrol & Pretest_Kelas_Eksperimen \\
\hline Mean & 51,77 & 52,10 \\
\hline Median & 50,00 & 50,00 \\
\hline Std. Deviation & 5,708 & 6,554 \\
\hline Minimum & 40 & 40 \\
\hline Maximum & 65 & 65 \\
\hline
\end{tabular}

Dari tabel di atas dapat diketahui ratarata nilai pretest untuk kelas kontrol dan kelas eksperimen tidak terlalu jauh berbeda. Rata-rata kelas kontrol mempunyai nilai 51,77 dan kelas eksperimen mempunyai rata-rata sebesar 52.10. Setelah diketahui nilai pretest untuk kelas kontrol dan kelas eksperimen dilakukan uji independent sample t-test sebagai berikut : 
Tabel 3. Hasil Uji Independent Sample T-test Pretest

\begin{tabular}{|c|c|c|c|c|c|c|c|c|c|c|}
\hline & \multicolumn{2}{|c|}{$\begin{array}{c}\text { Levene's } \\
\text { Test for } \\
\text { Equality of } \\
\text { Variances }\end{array}$} & \multicolumn{7}{|c|}{ t-test for Equality of Means } \\
\hline & & \multirow[b]{2}{*}{$F$} & \multirow[b]{2}{*}{ Sig. } & \multirow[b]{2}{*}{$\mathrm{t}$} & \multirow[b]{2}{*}{ Df } & \multirow{2}{*}{$\begin{array}{l}\text { Sig. } \\
(2- \\
\text { tailed })\end{array}$} & \multirow{2}{*}{$\begin{array}{l}\text { Mean } \\
\text { Differe } \\
\text { nce }\end{array}$} & \multirow{2}{*}{$\begin{array}{c}\text { Std. } \\
\text { Error } \\
\text { Differen } \\
\text { ce }\end{array}$} & \multicolumn{2}{|c|}{$\begin{array}{l}95 \% \text { Confidence } \\
\text { Interval of the } \\
\text { Difference }\end{array}$} \\
\hline & & & & & & & & & Lower & Upper \\
\hline $\begin{array}{l}\text { Nilai } \\
\text { Prete }\end{array}$ & $\begin{array}{c}\text { Equal variances } \\
\text { assumed }\end{array}$ & .632 & .430 & -.207 & 60 & .837 & -.323 & 1.561 & -3.445 & 2.800 \\
\hline st & $\begin{array}{c}\text { Equal variances } \\
\text { not assumed }\end{array}$ & & & -.207 & 58.889 & .837 & -.323 & 1.561 & -3.446 & 2.801 \\
\hline
\end{tabular}

Berdasarkan tabel diatas, diperoleh nilai $\mathrm{t}$ hitung untuk pretest sebesar $-0,207$ dan $-0,207$, nilai tersebut lebih kecil dari t tabel yaitu $0,207<1.670$. Nilai signifikannya lebih besar dari 0,05 yaitu 0,837>0,05. Sehingga dapat disimpulkan bahwa tidak ada perbedaan nilai pretest antara kelas eksperimen maupun kelas kontrol.
Dengan demikian kemampuan pemahaman kelas tersebut sama.

Deskripsi data hasil penelitian nilai postest untuk kelas eksperimen yang telah diberikan perlakukan menggunakan strategi pembelajaran active knowledge sharing dan kelas kontrol dengan menggunakan strategi pembelajaran problem based learning dapat disajikan pada tabel berikut :

Tabel 4. Nilai Postest Kelas Kontrol dan Kelas Eksperimen

\begin{tabular}{|c|r|r|}
\hline & Postest_Kelas_Kontrol & Postest_Kelas_Eksperimen \\
\hline Mean & 67,58 & 73,06 \\
Median & 65.00 & 75,00 \\
Std. Deviation & 10,714 & 9,190 \\
Minimum & 50 & 55 \\
Maximum & 90 & 90 \\
\hline
\end{tabular}

Dari tabel di atas dapat diketahui rata-rata nilai postest untuk kelas kontrol dan kelas eksperimen terdapat perbedaan. Rata-rata kelas kontrol mempunyai nilai 67,58 dan kelas eksperimen mempunyai rata-rata sebesar 73,06 . Setelah diketahui nilai postest untuk kelas kontrol dan kelas 
eksperimen dilakukan uji independent sample t-test sebagai berikut

Tabel 5. Hasil Uji Independent Sample T-test Postest

\begin{tabular}{|c|c|c|c|c|c|c|c|c|c|c|}
\hline & \multicolumn{2}{|c|}{$\begin{array}{l}\text { Levene's } \\
\text { Test for } \\
\text { Equality of } \\
\text { Variances }\end{array}$} & \multicolumn{7}{|c|}{ t-test for Equality of Means } \\
\hline & & \multirow[b]{2}{*}{$\mathrm{F}$} & \multirow[b]{2}{*}{ Sig. } & \multirow[b]{2}{*}{$\mathrm{T}$} & \multirow[b]{2}{*}{ Df } & \multirow{2}{*}{$\begin{array}{l}\text { Sig. (2- } \\
\text { tailed) }\end{array}$} & \multirow{2}{*}{$\begin{array}{l}\text { Mean } \\
\text { Differe } \\
\text { nce }\end{array}$} & \multirow{2}{*}{$\begin{array}{c}\text { Std. } \\
\text { Error } \\
\text { Differenc } \\
\text { e }\end{array}$} & \multicolumn{2}{|c|}{$\begin{array}{l}95 \% \text { Confidence } \\
\text { Interval of the } \\
\text { Difference }\end{array}$} \\
\hline & & & & & & & & & Lower & Upper \\
\hline \multirow[t]{2}{*}{$\begin{array}{c}\text { Nilai } \\
\text { Prete } \\
\text { st }\end{array}$} & $\begin{array}{c}\text { Equal } \\
\text { variances } \\
\text { assumed }\end{array}$ & .857 & 358 & 2.163 & 60 & .035 & 5.484 & 2.535 & .413 & 10.555 \\
\hline & $\begin{array}{c}\text { Equal } \\
\text { variances not } \\
\text { assumed } \\
\end{array}$ & & & 2.163 & $\begin{array}{c}58 . \\
64 \\
2\end{array}$ & .0 .35 & 5.484 & 2.535 & 410 & 10.557 \\
\hline
\end{tabular}

Berdasarkan tabel di atas, diperoleh nilai t hitung untuk posttest sebesar 2.163 dan 2.163, nilai tersebut lebih besar dari t tabel yaitu $2.163>1,670$. Nilai signifikannya lebih kecil dari 0,05 yaitu $0,35>0,05$. Jadi dapat disimpulkan bahwa terdapat pengaruh positif antara penerapan strategi active knowledge sharing terhadap pemahaman matematika.

\section{Deskripsi Peningkatan N-Gain}

Nilai $N$-Gain didapat dari selisih skor pretes dan posttest, untuk mengetahui peningkatan siswa antara kelas eksperimen dan kelas kontrol digunakan perhitungan uji $\mathrm{N}$-gain. Berikut ini disajikan tabel deskripsi gain kelas eksperimen dan kelas kontrol: 
Tabel 6. Data Gain Kelas Eksperimen dan Kontrol

\begin{tabular}{|c|c|c|c|c|}
\hline Kelas & Pretest & Posttest & N-Gain & Kriteria \\
\hline Eksperimen & 52.10 & 73.06 & 0,55 & Sedang \\
\hline Kontrol & 51.77 & 67.56 & 0,41 & Sedang \\
\hline
\end{tabular}

Berdasarkan nilai pretest dan posttest pada kedua kelas tersebut, kelas eksperimen memperoleh $\mathrm{N}$-Gain sebesar 0,55 dan kelas kontrol memperoleh $\mathrm{N}$-Gain sebesar 0,41 . Setelah diinterpretasikan diperoleh $\mathrm{N}$-Gain kelas eksperimen sebesar 0,55 tergolong sedang, dan kelas kontrol nilai $\mathrm{N}$-Gain sebesar 0,41 tergolong sedang.

\section{PENUTUP}

\section{Simpulan}

Penggunaan strategi Active Knowledge Sharing di kelas VI MTsN 4 Kuningan berlangsung baik. Pembelajaran dengan menggunakan strategi tersebut siswa terlihat lebih aktif dan antusias dalam mengikuti proses kegiatan belajar mengajar. Proses ini berlangsung lebih mudah dipahami oleh siswa dan menyenangkan karena siswa bisa mengetahui setiap materi yang belum pernah disampaikan oleh guru sebelumnya, dan juga dituntut aktif berbagi pengetahuannya langsung kepada teman temannya. Strategi pembelajaran ini diharapkan siswa dapat lebih memahami materi pembelajaran dengan cepat dan membuat siswa aktif dalam kegiatan pembelajaran, juga melatih siswa agar dapat membentuk kerjasama tim. Hal ini mengingatkan bahwa strategi active knowledge sharing dapat menjadi pemicu semangat siswa dalam kegiatan pembelajaran sehingga dapat meningkatkan pemahaman matematika siswa . Kemampuan pemahaman matematika siswa dengan menggunakan strategi active knowledge sharing di MTsN 4 Kuningan mencapai nilai rata-rata 73,06 , sedangkan kemampuan pemahaman matematika siswa di kelas kontrol dengan menggunakan strategi pembelajaran problem based learning mencapai nilai rata-rata 67,56. Hal ini menunjukan perolehan nilai dari kelas eksperimen yang menggunakan strategi active knowledge sharing lebih besar dibandingkan dengan kelas kontrol yang menggunakan strategi problem based learning. Terdapat pengaruh dengan menggunakan strategi active knowledge sharing. hal ini dapat dilihat dari hasil nilai pretest kelas 
eksprimen sebesar 52,10 dan nilai posttest sebesar 73,06 serta dapat dilihat dari hasil pengujian hipotesis yang memperoleh nilai thitung lebih besar dari pada t tabel atau yaitu $2.163>1.670$ dan nilai signifikannya dibawah 0,05 yaitu $0,03<0,05$ untuk kelas eksperimen. Sedangkan untuk kelas kontrol perolehan nilai t hitung lebih besar dari ttabel atau $2.163>1.670$ dan nilai signifikannya lebih kecil dari 0,05 yaitu 0,03 $<0,05$. Hal ini menunjukan adanya peningkatan pada proses belajar yang baik antara kelas eksperimen dan kelas kontrol. Berdasarkan uji $\mathrm{N}$-Gain diperoleh nilai kelas eksperimen sebesar 0,55 yang berkriteria sedang dan untuk kelas kontrol diperoleh nilai sebesar 0,41 yang berkriteria sedang. Berdasarkan N-Gain tersebut peningkatan kemampuan pemahaman matematika yang menggunakan strategi active knowledge sharing lebih tinggi dibandingkan dengan kelas yang menggunakan strategi problem based learning. Dengan demikian dapat disimpulkan bahwa penggunaan strategi active knowledge sharing lebih efektif meningkatkan pemahaman matematika siswa dibandingkan dengan strategi problem based learning.

\section{Saran}

Berdasarkan hasil penelitian dan kesimpulan diatas, saran yang dapat penulis kemukakan adalah sebagai berikut: siswa, diharapkan dapat lebih berperan aktif dalam kegiatan pembelajaran dan mengambil pelajaran dari setiap kegiatan pembelajaran serta menjadi siswa yang percaya diri atas kemampuan yang diketahuinya; Guru, diharapkan dapat lebih memaksimalkan lagi dalam menggunakan dan menerapkan strategi pembelajaran yang mudah, aktif dan menyenangkan. Strategi pembelajaran active knowledge sharing dapat dipakai sebagai alternative dalam memberikan suatu variasi dalam kegiatan belajar mengajar dan proses pembelajaran; Sekolah, diharapkan dapat menyediakan fasilitas untuk menunjang guru dalam usahanya melaksanakan pembelajaran yang aktif, kreatif dan menyenangkan. Dengan demikian, sekolah harus selalu mendukung dan memotivasi guru untuk lebih kreatif dan inofatif dalam menerapkan strategi pembelajaran yang sesuai dengan harapan siswa.

\section{DAFTAR PUSTAKA}

Arifin, Zainal. 2017. Kriteria Instrumen Dalam Suatu Penelitian. Jurnal Theorems (The Original Research of Mathematics. (2)1. 31-32

Hartati. (2017). Pengaruh Kemampuan

Pemahaman Konsep, Kemampuan Komunikasi dan Koneksi Terhadap Kemampuan Pemecahan Masalah. Journal of Mathematics Education Science \& Technology. (2). 1, 22 Nafi'a, Asri. 2001. Proceeding Biology Education Conference : Biology, 
science, Enviromental, and learning. Jurnal FKIP.UNS. 9 (1) 29

Probst, Gilbert. 2001. Managing Knowledge Building Block For Success.(24)

Sugiyono. 2009. Statistika untuk Penelitian. (Bandung: Alfabeta).

Sugiyono. 2010. Metodologi Penelitian Pendidikan. Bandung: Alfabeta.

Uno. Haamzah B. 2009. Mengelola Kecerdasan Dalam Pembelajaran. Jakarta : Bumi Aksara

Yohanes, Feri. (2018). Analisis Pemahaman Konsep Berdasarkan Taksonomi Bloom Dalam Menyelesaikan Soal Keliling dan Luas Segitiga Bagi Siswa Kelas VIII. Jurnal Mitra Pendidikan. (2)1. 26

Zaini, Hisyam. 2007. Strategi

Pembelajaran Aktif. Yogyakarta:

Pustaka Insan Madani. 